\title{
Study of the Discoloration Rate of Rhodamine B as a Function of the Operating Parameters at Pt and BDD Electrodes
}

\author{
H.A. Mallah, D.M. Naoufal, A.I. Safa and M.M. El Jamal ${ }^{*}$ \\ Chemistry Department, Faculty of Sciences (I), Lebanese University, El Hadath, Lebanon
}

Received 19 June 2013; accepted 28 June 2013

\begin{abstract}
The chemical reaction of rhodamine B by electro-generated species using Pt and BDD electrodes was performed. The product(s) of this chemical reaction are related to the supporting electrolyte and electrolysis time. The rate of discoloration is affected by the current density, initial $\mathrm{pH}$, temperature, and the nature of the supporting electrolyte. However, the initial dye concentration and the ionic strength did not show any significant effect on both electrodes. Discoloration of the dye and mineralization were not observed in presence of sulfate and nitrate with the Pt electrode, but occurred slowly with the $\mathrm{BDD}$ electrode. In the presence of $\mathrm{KCl}$ and $\mathrm{KBr}$, the discoloration was very fast with both electrodes, and was accompanied with partial degradation. In the presence of $\mathrm{KCl}$, the colorless rhodamine $\mathrm{B}$ solution turned rose after several hours of being set at rest.
\end{abstract}

Keywords: Pt and BDD electrodes, discoloration, Rhodamine B, sulfate, chloride.

\section{Introduction}

The xanthene dyes such as Eosin Y, rose Bengal, and rhodamine B have been proved to be a very useful class of luminescent and triplet forming dyes for theoretical studies and practical applications. The importance of these probes is due to their photophysical and photochemical behavior with the environment [1]. These dyes are water-soluble, and thus they can be adsorbed on all kinds of natural and synthetic fibers. They are also used to color plastics, and leather [2]. Some xanthene dyes, have been reported to be toxic to various insect species in the laboratory [3-7]. The neurotoxicity and carcinogenicity of xanthene dyes to humans and animals have also been experimentally proven $[8,9]$.

\footnotetext{
* Corresponding author. E-mail address: mjamal@ul.edu.lb
} 
Several physicochemical processes such as adsorption, filtration, coagulation/ flocculation, and electrocoagulation have been used to remove dyes from water. However, these physical processes are separatives but not degradatives.

Furthermore, the biological treatments of wastewater are often not recommended due to the toxicity of the dyes to micro-organisms.

The degradation of basic dyes by chemical oxidation has been widely tested in several laboratories. Examples of oxidants are: persulfate [10 - 13], $\mathrm{O}_{3}$ [14], $\mathrm{UV} / \mathrm{O}_{3}$ [15], activated $\mathrm{O}_{2}$ [16], Fenton's reagent [17, 18], photo Fenton [19], $\mathrm{H}_{2} \mathrm{O}_{2}$ [20], and photodegradation using $\mathrm{TiO}_{2}$ [21- 26].

In recent years, the use of electrochemical technologies has shown a great interest because they offer effective means to solve environmental problems related to industrial processes, and are adaptable to a wide range of dyes [27-31]. Electrochemical methods for wastewater treatment mainly involve the direct and indirect electrochemical oxidation [32-34]. In indirect oxidation, the main oxidizing agents are $\mathrm{Cl}_{2}$ and $\mathrm{HOCl}[33,35]$. Chlorine molecules have the ability to mineralize organic molecules quickly, but they can interact easily with organic molecules to form carcinogenic halogenated compounds [36-38].

The efficiency of the electrochemical oxidation of dyes is a function of the electrode and the supporting electrolyte [38-46]. At Pt electrode, the supporting electrolyte is divided into two types: inactive such as sulfate and nitrate, and active such as chloride (production of $\mathrm{Cl}_{2}$, and $\mathrm{HClO}$ ). The discoloration rate of rhodamine $\mathrm{B}$ ( $\mathrm{Rhd} \mathrm{B}$ ) observed at the $\mathrm{RuO}_{2}-\mathrm{PdO}-\mathrm{TiO}_{2} / \mathrm{Ti}$ electrode was faster than those with one component electrodes [43]. The total mineralization of Rhd B was observed with $\mathrm{OH}^{*}$, which was electrogenerated by the electro-Fenton process, with Pt and BDD electrodes [44]. Therefore, it is of interest to study the effect of some experimental parameters such as $\mathrm{pH}$, temperature, current intensity, and others, on the discoloration rate of rhodamine $\mathrm{B}$ with $\mathrm{Pt}$ and BDD anodes in the presence of $\mathrm{KCl}$, nitrate, and sulfate.

\section{Experimental}

Rhodamine B (Fig. 1) was purchased from Sigma $\left(\mathrm{C}_{28} \mathrm{H}_{31} \mathrm{~N}_{2} \mathrm{O}_{3} \mathrm{Cl}\right.$, CAS: 81-88-9, MW: $479.02 \mathrm{~g}$ ), while the other chemical reagents were purchased from BDH (Analar or GPR). In order to study the discoloration by indirect oxidation with $\mathrm{Pt}$ and BDD electrodes, $100 \mathrm{mgL}^{-1}$ of Rhd B solution were prepared in distilled water. The concentration of the dye in the reaction mixture was selected in such a way that the absorbance of the dye at $550 \mathrm{~nm}$ followed Beer's law $\left(\mathrm{A}_{550}: 0.194 \mathrm{x}\right.$ [Rhd B] in $\mathrm{mg} \mathrm{L}^{-1}, \mathrm{R}^{2}$ : 0.998). The majority of the experiments were done at room temperature $(293 \mathrm{~K})$, in the presence of $8 \mathrm{mgL}^{-1} \mathrm{Rhd} \mathrm{B}, 0.1 \mathrm{M} \mathrm{KX}\left(\mathrm{X}=\mathrm{Cl}^{-}\right.$, $\mathrm{Br}^{-}$) or $0.1 \mathrm{M}$ sulfate, at $\mathrm{pH} 2$, with a current of $5 \mathrm{~mA}$. Experiments were carried out in a single combined electrolytic cell. The electrolyzed solution was prepared by mixing $8 \mathrm{~mL}$ of $100 \mathrm{mgL}^{-1}$ of Rhd $\mathrm{B}, 10 \mathrm{~mL}$ of $0.1 \mathrm{M} \mathrm{H}_{2} \mathrm{SO}_{4}, 10 \mathrm{~mL}$ of $1 \mathrm{M}$ supporting electrolyte and $72 \mathrm{~mL} \mathrm{H}_{2} \mathrm{O}$.

The Pt wire electrodes (d: $1.5 \mathrm{~mm}, 1: 15 \mathrm{~mm}$ ) were purchased from Taccusel (France), and the bipolar BDD electrodes (plate: 50x25x3 mm) from NeoCoaT 
(Switzerland). The distance between the two electrodes is $5 \mathrm{~cm}$. The electrolysis was done in Chrono-Amperostat, type CEAMD-6, from Taccusel.<smiles></smiles>

Figure 1: Structure of rhodamine B.

\begin{abstract}
Absorption spectra were recorded on a double beam UV- Visible Specord 200 spectro-meter (Analytic Jena, AG Germany) and the fluorescence spectra were recorded on LS-50B (PerkinElmer) spectrofluorimeter equipped with a Xenon discharge lamp, $1 \mathrm{~cm}$ quartz cell $\left(\lambda_{\mathrm{ex}}: 550 \mathrm{~nm}, \lambda_{\mathrm{em}}: 578 \mathrm{~nm}\right)$. Schott Gerate CG $819 \mathrm{pH}$-meter Schott Gerate CG $819 \mathrm{pH}$-meter was used to measure $\mathrm{pH}$.

In order to determine the discoloration rate of the dye and the effect of the experimental parameters, the visible spectra of the solution were recorded at various times of the electrolysis. The slope of the line $A_{550}$ vs. time $\left(k_{o b s}\right)$ yielded an explanation about the discoloration rate value. The discoloration was studied as a function of several parameters such as the concentration of dye, the initial $\mathrm{pH}$, the nature and the concentration of the electrolyte, the intensity of the current, and ionic strength.
\end{abstract}

\title{
Results and discussions
}

\section{Electrolysis with Pt/Pt electrodes}

Visible spectroscopy analysis

The discoloration of Rhd B was not observed in the presence of sulfate or nitrate at any $\mathrm{pH}$ (no direct reaction with Pt electrode). However, in the presence of 0.1 $\mathrm{M} \mathrm{KCl}$ short time (8 min., $\mathrm{pH}$ : 2) was sufficient for total discoloration (Fig. 2). The time required for total discoloration was a function of the operational parameters which will be discussed later. No wavelength shift was observed during the discoloration of Rhd B as was the case with fluorescein (red shift) [37]. The absorbance (or the fluorescence) in the whole spectrum decreases during the electrolysis, which means that there are no fixation of chlorine on the aromatic rings of $\mathrm{Rhd} \mathrm{B}$ and no $\mathrm{N}$ - deethylation, in contrast to the results reported by Watanabe et al. and by Zhao et al. (Fig. 2) [47, 48]. The evolutions of the visible spectra during electrolysis are similar to those obtained with Wenqi et al. and Ben Salah et al. $[15,46]$. No colored intermediates were detected during the oxidation of Rhd B since the TLC test at different electrolysis times showed only one colored spot, corresponding to Rhd B. The oxidation mechanism of Rhd $B$ with chlorine is different from that with persulfate because several colored spots were observed on TLC with persulfate [49]. The absorbance $\mathrm{A}_{550}$ (inset of Fig. 2) or the fluorescence signal $\left(S_{578}\right)$ decreases linearly with time. The addition 
of Rhd B solution to a freshly saturated solution with electro-generated chlorine species leads to a sudden discoloration of Rhd $\mathrm{B}$. This means that the reaction between chlorine species and Rhd B is very fast. Therefore, the procedure used to measure the absorbance is not suitable for the determination of the order of the reaction. However the slope of the line $A_{550}$ vs. time is useful to study the effect of the operational parameters on the discoloration rate.

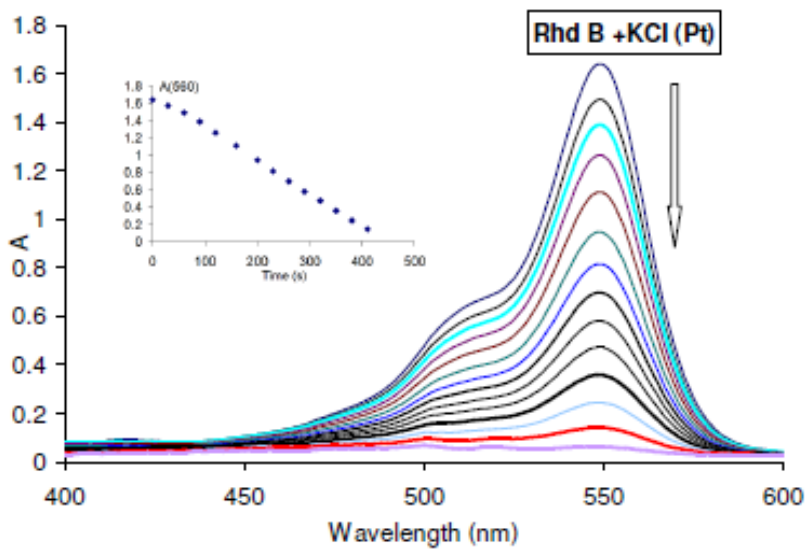

Figure 2. Variation of the visible spectrum of Rhd $\mathrm{B}$ as a function of electrolysis time at Pt electrode (0 s - $400 \mathrm{~s})\left(10 \mathrm{mgL}^{-1} \mathrm{Rhd} \mathrm{B,} 0.1 \mathrm{M} \mathrm{KCl}, 5 \mathrm{~mA}, \mathrm{pH}_{\mathrm{o}}: 2,293 \mathrm{~K}\right)$.

\section{Effect of Rhd B concentration}

At $\mathrm{Pt}$ electrode, the degradation rate (slope of the line $\mathrm{A}_{550}$ vs. time) is approximately the same when the concentration varies in the range $4 \mathrm{mgL}^{-1}-10$ $\mathrm{mgL}^{-1}$, but the time needed to have total discoloration is proportional to the concentration of Rhd B. The result is in accordance with the linear variation of $\mathrm{A}$ $(550 \mathrm{~nm})$ as a function of electrolysis time (inset in Fig. 2).

\section{Effect of the nature of the supporting electrolyte}

It is interesting to investigate the effect of the nature of the strong electrolyte added on the discoloration rate (with $\mathrm{Pt}$ electrode). The electrolysis is done in presence of $0.1 \mathrm{M}$ of the following supporting electrolytes: $\mathrm{Na}_{2} \mathrm{SO}_{4}, \mathrm{NaNO}_{3}$, $\mathrm{KCl}, \mathrm{KBr}$ and $\mathrm{KI}$ (each added separately). The results show that discoloration in presence of sulfate or nitrate did not occur. The addition of KI to Rhd B solution provoked the precipitation of Rhd $\mathrm{B}$. The rate of precipitation is proportional to iodide concentration. Therefore, it is possible to eliminate Rhd B from aqueous solution by precipitation. The discoloration of $\mathrm{Rhd} \mathrm{B}$ in the presence of $\mathrm{KCl}$ and $\mathrm{KBr}$ is efficient and fast. However, for the same concentration of electrolyte, it is $\sim 10$ times faster with $\mathrm{KBr}$ than with $\mathrm{KCl}$.

\section{Effect of $p H$}

It is well understood that $\mathrm{pH}$ is one of the important factors that affect the performance of the electrochemical process. Rhd B has no acid-base property, so the general shape and the absorbance of the dye is independent of the $\mathrm{pH}$ of the solution $(2<\mathrm{pH}<11)$. However, the oxidant strength of chlorine is a function of $\mathrm{pH}$. Electrolysis at different initial $\mathrm{pH}\left(\mathrm{pH}_{\mathrm{o}}\right)$ shows that the discoloration rate of 
Rhd $\mathrm{B}$ increases linearly with the decrease in $\mathrm{pH}_{\mathrm{o}}$ (Table 1). This is due to the increase in $\mathrm{HClO} / \mathrm{Cl}_{2}$ amount in acidic medium, which has higher standard potential than that of $\left(\mathrm{ClO}^{-} / \mathrm{Cl}^{-}\right)$. Similar results were reported for the degradation of azo dyes [34] and methylene blue [38]. No effect of $\mathrm{pH}$ is observed in the presence of $\mathrm{KBr}$.

Table 1. Effect of the operational parameters on the discoloration rate of $\mathrm{Rhd} \mathrm{B}$ at $\mathrm{Pt}$ electrode.

\begin{tabular}{|c|c|}
\hline Parameter & $\mathrm{k}_{\mathrm{obs}} \mathrm{x} 10^{3}$ \\
\hline Rhd B concentration* & No effect \\
\hline $\begin{array}{l}\text { Initial } \mathrm{pH}(\mathrm{KCl})^{*} \\
\text { Initial } \mathrm{pH}(\mathrm{KBr})^{*}\end{array}$ & $\begin{array}{c}-0.447 x[\mathrm{pH}]+5.34, \quad \mathrm{R}^{2}: 0.997 \\
\text { No effect }\end{array}$ \\
\hline [Strong electrolyte]* & $\begin{array}{c}\text { 43. } 2 x[\mathrm{KCl}], \mathrm{R}^{2}: 0.98 \\
744 x[\mathrm{KBr}]^{2}+631 \times[\mathrm{Br}], \mathrm{R}^{2}: 0.99 \\
\text { No discoloration (with } \mathrm{Na}_{2} \mathrm{SO}_{4} \text { ) }\end{array}$ \\
\hline Current intensity $(\mathrm{KCl})^{*}$ & $0.965 x \mathrm{I}(\mathrm{mA}), \mathrm{R}^{2}: 0.993$ \\
\hline Ionic force* & No effect \\
\hline Effect of temperature & $-0.188 \times \mathrm{x}(\mathrm{K})+61.2, \mathrm{R}^{2}: 0.993$ \\
\hline
\end{tabular}

\section{Effect of halide salt concentration}

To study the effect of $\mathrm{KCl}$ concentration on the discoloration rate, the electrolysis is done with $8 \mathrm{mgL}^{-1}$ of Rhd B solution at $\mathrm{pH}_{\mathrm{o}}: 2$, with $5 \mathrm{~mA}$. Linear relation is observed between $\mathrm{KCl}$ concentration and the discoloration rate, but it is polynomial (equation of $2^{\text {nd }}$ degree) with $\mathrm{KBr}$ (Table 1). This result confirms the discoloration of the organic compounds via the electro-generated halide species $[29,30]$.

\section{Effect of ionic strength}

The effect of the ionic strength on the discoloration rate of Rhd $\mathrm{B}$ was investigated with $8 \mathrm{mgL}^{-1}$ of Rhd $\mathrm{B}$ solution, at $\mathrm{pH}_{\mathrm{o}}: 2$, with $2.5 \mathrm{~mA}$, and in the presence of $0.1 \mathrm{M} \mathrm{KCl}$ by varying the concentration of $\mathrm{Na}_{2} \mathrm{SO}_{4}$ or $\mathrm{NaNO}_{3}$ in the medium $(0.03 \mathrm{M}-0.2 \mathrm{M})$. The results obtained showed no effect of the ionic strength on the discoloration rate $\left(\mathrm{k}_{\mathrm{obs}} \sim\right.$ constant $)$.

\section{Effect of current intensity}

Current intensity is an important variable in electrolysis. The generation of chlorine species by electrolysis was done in acidic medium $\left(\mathrm{pH}_{\mathrm{o}}: 2\right)$ in presence of $8 \mathrm{mgL}^{-1}$ Rhd $\mathrm{B}$ and $0.1 \mathrm{M} \mathrm{KCl}$, at several constant currents ranging from $1 \mathrm{~mA}$ to $20 \mathrm{~mA}$. The results depict that the discoloration rate increases linearly with the increase of the current intensity (Table 1). 
Linear relation was also observed with other organic compounds [37, 38]. The increase in discoloration rate with the applied current is due to the increase in the production of active chlorine products.

\section{Effect of temperature}

In general, any increase in temperature decreases the solubility of $\mathrm{Cl}_{2}(\mathrm{~g})$ in aqueous solution and therefore decreases the discoloration rate of the dyes (Table 1). The discoloration rate decreases from $6.36 \times 10^{-3}$ a.u. to $3.93 \times 10^{-3}$ a.u. when the temperature increases from 293 to $306 \mathrm{~K}$. This behavior was also observed with another xanthene dye [37].

\section{Effect of electrolysis time}

It was observed that when the electrolysis was stopped just after discoloration (8 $\mathrm{min}$ ) or after longer time $(30 \mathrm{~min})$, the transparent solution re-gained its color slowly. The reappearance of the color is function of light and temperature. At room temperature, and under indoor light, it takes one week for the development of the color (with successive blue shift of $A_{\max }$ from 540 to $510 \mathrm{~nm}$ ) (Fig. 3a), but in sunlight it takes one day only. The final product (compound X) is fluorescent and the color of its aqueous solution (red- orange, $\lambda_{\max } \sim 510 \mathrm{~nm}, \lambda_{\mathrm{em}}: 530 \mathrm{~nm}$ ) is different from that of Rhd B (red, $\lambda_{\max }: 550 \mathrm{~nm}$ ). The UV spectrum of Rhd B is approximately similar to that of the final product (bands at: 250, 290 and 340 $\mathrm{nm})$. Apparently the electro-generated chlorine species did not breakdown Rhd B totally, but leads to a product with minor change in the functional group attached to the aromatic rings. In order to prevent the formation of the fluorescent colored compound and have total mineralization, the electrolysis was allowed to continue for a longer time (3h, $8 \mathrm{~h}$, and $16 \mathrm{~h}$ ) (Fig. 3b), but this tentative has failed, since a precipitate with light pink color is obtained after putting the solution at rest overnight. After 3-4 h of electrolysis, the Rhd B solution became transparent in UV zone, because the slightly pink water insoluble product floats on the surface of the solution or precipitates on the immersed part of the electrode. This result is well in line with that obtained with Chen et al. [45]. The precipitate is insoluble in DMSO and acetone, but soluble in ethanol $\left(\lambda_{\max }: 510 \mathrm{~nm}\right)$, and its NMR and FTIR spectra showed the presence of aromatic $\mathrm{H}$ and aromatic $\mathrm{C}=\mathrm{C}$ respectively. Therefore, based on the $\lambda_{\text {em }}(530 \mathrm{~nm})$ of the slightly pink precipitate and the FTIR and NMR data obtained we can deduce that the slightly pink precipitate is not a simple aromatic molecule.

\section{Electrolysis with BDD/BDD electrodes}

In the presence of $\mathrm{KCl}$, the replacement of the Pt electrode by $\mathrm{BDD}$ electrode gave approximately the same colored compound and the same precipitate, since in both cases $\mathrm{Cl}_{2}$ is generated at the anode. For the same $\mathrm{KCl}$ concentration, the discoloration rate is as fast as with Pt electrode (Fig. 4a). In the presence of sulfate, the discoloration occurred with BDD electrode slowly ( $\sim 8$ times slower than in the presence of $\mathrm{KCl}$ (Fig. 4b). No recoloration and no formation of the slightly pink precipitate after setting the electrolysis at rest. This might imply total mineralization. Therefore, the discoloration of Rhd B with sulfate at BDD 
electrode is convenient for wastewater treatment. The results obtained with BDD electrode in the presence of sulfate are in accordance with those of Ben Salah et al. [46] and with Oturan et al. in the presence of $\left(\mathrm{O}_{2}+\mathrm{Fe}(\mathrm{II})\right)$, since in both cases $\mathrm{OH}$ radical is reacted with $\mathrm{Rhd} \mathrm{B}$ [44]. The disagreement of our results in using $\mathrm{Pt}$ and $\mathrm{BDD}$ electrodes in the presence of $\mathrm{KCl}$, with those of Oturan et al. is attributed to the nature of the electro-generated species. In the presence of sulfate, the discoloration rate increases with the increase in current intensity $\left(\mathrm{k}_{\mathrm{obs}}\right.$ : $\left.0.3 \times 10^{-4} \times \mathrm{I}(\mathrm{mA}), \mathrm{R}^{2}: 0.92\right)$, with the decrease in $\mathrm{pH}\left(\mathrm{k}_{\mathrm{obs}}: 2 \times 10^{-4} \mathrm{xpH}^{-0.58}\right.$, $\left.\mathrm{R}^{2}: 0.92\right)$, but it is independent of the Rhd $\mathrm{B}$ concentration. The discoloration rate in the presence of nitrate is higher than that with sulfate at $\mathrm{pH}: 2$, but at neutral $\mathrm{pH}$, it is much slower.
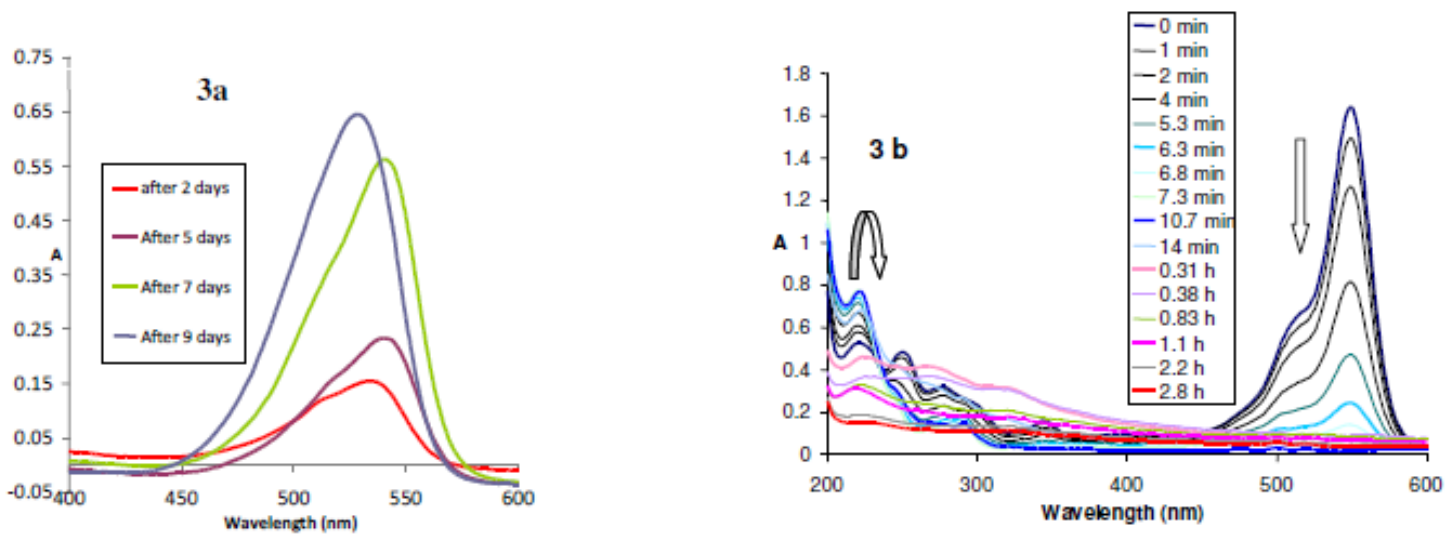

Figure 3. a: Reappearance of color with time after stopping electrolysis; b: evolution of the UV-Visible spectrum of Rhd $\mathrm{B}$ during long time of electrolysis at Pt electrode in presence of $\mathrm{KCl}\left(10 \mathrm{mgL}^{-1} \mathrm{Rhd} \mathrm{B,} 0.1 \mathrm{M} \mathrm{KCl}, \mathrm{pH}_{\mathrm{o}}: 2,5 \mathrm{~mA}, 293 \mathrm{~K}\right)$.
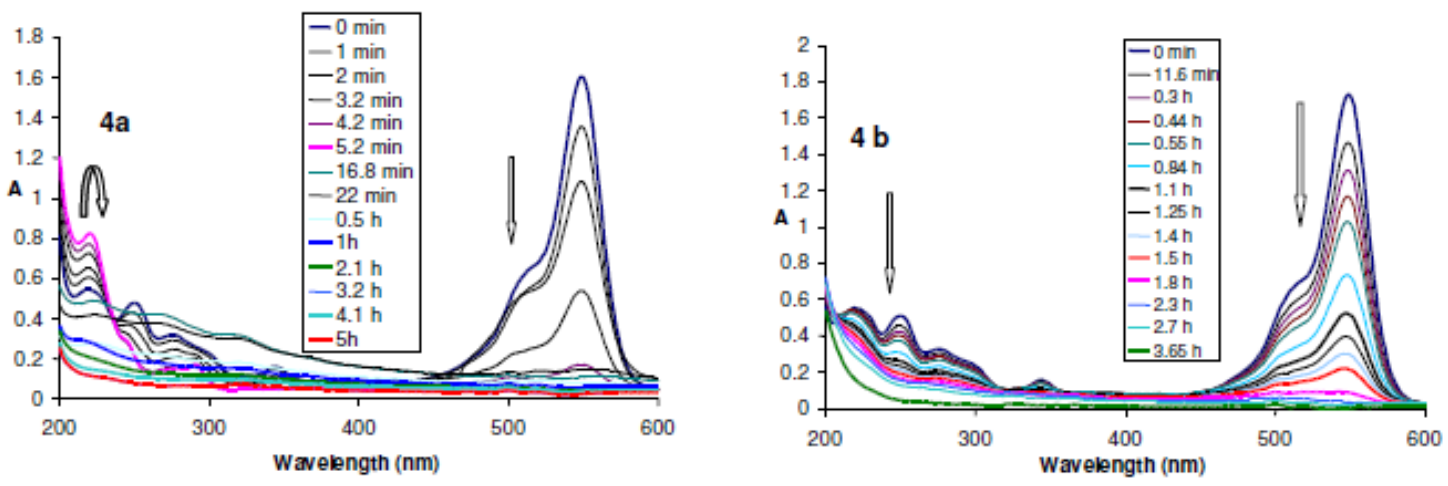

Figure 4. Evolution of the UV-Visible spectrum during long time of electrolysis at BDD electrode in presence of $0.1 \mathrm{M} \mathrm{KCl}(\mathbf{a})$ and in presence of $0.1 \mathrm{Na}_{2} \mathrm{SO}_{4}(\mathbf{b})(10 \mathrm{mg}$ $\mathrm{L}^{-1}$ Rhd B, $\left.\mathrm{pH}_{\mathrm{o}}: 2,5 \mathrm{~mA}, 293 \mathrm{~K}\right)$.

\section{Conclusion}

The discoloration of Rhd B using Pt and BDD electrodes in the presence of $\mathrm{KCl}$ and $\mathrm{KBr}$ is fast, but no mineralization occurred under these conditions even for an extended electrolysis time. The discoloration and the mineralization of Rhd B using BDD electrode are slow in the presence of sulfate and nitrate. The 
discoloration using $\mathrm{Pt}$ electrode increases with the increase in the current intensity and $\mathrm{KCl}$ concentration, but decreases with the increase in $\mathrm{pH}$ and temperature. The discoloration rate is independent of the Rhd $\mathrm{B}$ concentration and the ionic strength. The effects of the operating parameters on the discoloration rate using BDD and Pt electrodes are similar.

\section{Acknowledgment}

The authors wish to thank Prof. M. El Masri for her help and review, and the "Ecole Doctorale de Sciences et Technologie" at The Lebanese University for the financial aid.

\section{References}

1. Madge D, Rojas GE, Seybold PG, Photochem Photobiol. 1999; 70(5): 737

2. $\quad$ Li Y, Teng CP, Zhang S, et al. Adv Mater.,2011;23:1463.

3. Pimprikar GD, Heitz JR, J Miss Acad Sci. 1984;29:77.

4. Pimprikar GD, Fondren JE, Greer Jr DS, et al. The Southwestern Entomol. 1984;9:218.

5. Capinera JL, Squitier JM. J Econ Entomol. 2000;93:662.

6. Berni J, Rabossi A, Pujol-Lereis LM, et al. Pesticide Biochem Physiol. 2009; 95: 12.

7. Amor TB, Jori G. Insect Biochem Molecular Biol. 2000;30:915.

8. Jones CL, Ranganathan S, Hood RD, Teratology. 1986;33:67C.

9. Nestmann ER, Douglas GR, Matula TI, et al. Cancer Research. 1979;39:4412.

10. Gokulakrishnan S, Parakh P, Prakash H, J Haz Mat. 2012;213:19.

11. Djebbar K, Aliouche S, Chenini H, et al. Desalination. 2009;250:76.

12. Lin Y-T, Liang C, Chen J-H. Chemosphere. 2011;82:1168.

13. Fayoumi LMA, Ezzedine MA, Akel HH, et al. Port Electrochim Acta. 2012;30:121.

14. Kusvuran E, Gulnaz O, Samil A, et al. J Haz Mat. 2011;186:133

15. Cuiping B, Xianfeng X, Wenqi G, et al. Desalination. 2011;278:84.

16. Deng KJ, Huang F, Wang DY, et al. Chinese Chem Letters. 2004;15:1223.

17. Fan H-J, Huang S-T, Chung W-H, et al. J Haz Mat. 2009;171:1032.

18. Hameed BH, Lee TW. J Haz Mat. 2009;164:468.

19. Kumar A, Paliwal M, Ameta R, et al. Indian J Chem Technol. 2008;15:7.

20. Edwards JC. MSc Thesis. Blacksburg, Virginia;2000.

21. Oliveira EGL, Rodrigues JJ, Oliveira HP. Chem Eng J. 2011;172: 6.

22. Wilhelm P, Stephan D. J Photochem Photobiol A: Chemistry. 2007;185:19.

23. Aliabadi M, Sagharigar T. J Appl Environ Biol Sci. 2011;12:620.

24. Li J, Li L, Zheng L, et al. Electrochim Acta. 2006;51:4942.

25. Soares BET, Lansarin MA, Moro CC. Braz J Chem Eng. 2007;24:29.

26. Wu J-M, Zhang T-W. J Photochem Photobiol A: Chemistry. 2004;162:171.

27. Santos V, Morão A, Pacheco MJ, et al. J Environ Eng Manage. 2008;18:193.

28. Martınez-Huitle CA, Ferro S. Chem Soc Rev. 2006;35:1324. 
29. Peralta-Hernandez JM, Mejia S, Godinez LA, et al. Environ research. Kerala, India: M Palomar Ed.;2005.

30. Palma-Goyes RE, Guzmn-Duque FL, Peuela G, et al. Chemosphere. 2010; $81: 26$.

31. Polacro M, Palmas S, Renoldi F, et al. J Appl Electrochem. 1999; 29:147.

32. Wu M, Zhao G, Li M, et al. J Haz Mat. 2009;163:26.

33. Abu Ghalwaa NM, Abdel-Latif MS. J Iranian Chem Soc. 2005;2:238.

34. Alameddine I, El Jamal MM. J Chem Technol Metall (Sofia). 2009;44:127.

35. Panizza M, Barbucci A, Ricotti R, et al. Sep Purif Technol. 2007;54:382.

36. Donaldson JD, Grimes SM, Yasri NG, et al. J Chem Technol Biotechnol. 2002;77:756.

37. Raidan RI, Tabbara A, El Zant AA, et al. J Chem Tech Metall (Sofia). 2009;44:79.

38. El Hajj Hassan MA, El Jamal M.M. Port Electrochim Acta. 2012;30:351.

39. Peralta-Hernandez JM, Mendez-Tovar M, Guerra-Sanchez R, et al. Int J Electrochem. 2012:154316.

40. Zaviska F, Drogui P, Blais J-F, et al. J Appl Electrochem. 2009;39:2397.

41. Rajkumar D, Jong Guk K. J Haz Mat. 2006;B136:203.

42. Abu Ghalwa NM, Zaggout FR. J Environ Sci Health A. 2006;41:2271.

43. $\mathrm{Du} \mathrm{L}, \mathrm{Wu}$ J, Hu C. Electrochim Acta. 2012;68:69.

44. Khalfaoui N, Boutoumi H, Khalaf $\mathrm{H}$, et al. Current Org Chem. 2012;16:2083.

45. Zheng Y-M, Yunus RF, Nanayakkara KGN, et al. Ind Eng Chem Res. 2012;51:5953.

46. Bensalah N, Abdel-Wahab A. Air, Soil Water Research 2010;3:45.

47. Watanabe T, Takirawa T, Honda K. J Phys Chem. 1977;81:1845

48. Hu X, Mohamood T, Ma W, et al. J Phys Chem B 2006;110:26012

49. Mcheik AH, El Jamal MM, accepted in J Chem Tech Metall (Sofia). 